\title{
Towards the Application of Augmented Reality in the Mining Sector: Open-Pit Mines
}

\author{
Olivier Hugues \\ ESTIA Research, UQAT \\ Technopole Izarbel \\ Bidart, France
}

\author{
André Gbodossou \\ UQAT, QC, Canada \\ Rouyn-Noranda \\ QC, Canada
}

\author{
Jean-Marc Cieutat \\ ESTIA Research \\ Technopole Izarbel \\ Bidart, France
}

\begin{abstract}
This article put augmented reality technology, and its application in the mining sector, in perspective. The current vitality in the mining sector in Canada, and particularly in the province of Quebec, is leading decision-makers to use new technologies in a sector which is nevertheless quite traditionalist. An exploration of the different activities connected to mining operations in order to identify the potential relevance of the use of augmented reality in this sector is shown. This analysis put forward some courses of action for improvement and development, from a technical and technological point of view, in order to support the applicability of augmented reality in the mining sector.
\end{abstract}

\section{General Terms:}

[A.I] Introductory and Survey - [H.5.I] Artificial, augmented, and virtual realities.

\section{Keywords:}

Augmented reality, open-pit mines

\section{INTRODUCTION}

The development of the technology needed to create an augmented reality system allows us to see this type of technology in many sectors of activity, today. Whether marketing [20], training assistance [7], navigational aid [15], maintenance aid [3, 12] or in gaming [28], augmented reality is used in a number of fields. At the same time, the mining sector is currently in a period of rapid expansion. The boom in the mining sector is primarily caused by the current dynamic of raw material prices, and by the significant growth of demand in China and in India [21]. Many mines whose operations had been halted due to a lack of profitability have since reopened, and the number of new mines being put into service is constantly increasing, in all countries which have mineral resources at their disposal. As part of a research project, we had been present on-site, at a Canadian mining project. This article intends to explore the potentialities for the use of augmented reality in the mining sector, and more specifically, in an open-pit mine. First, this paper will describe the open-pit mining project, to subsequently provide an overview of the different skill areas within this type of mine, so as to emphasize the potential uses of an augmented reality system. Following this, we put forward some courses of action and working perspectives intended to better integrate augmented reality into the mining sector.

\section{MOTIVATIONS}

During the course of modern mine operations, three major areas of activity, each of the three corners of a triangle, guide the work of the individuals on the site (Figure 1). One corner corresponds to health and safety in the workplace. The second involves constraints related to the environment, and the third re-

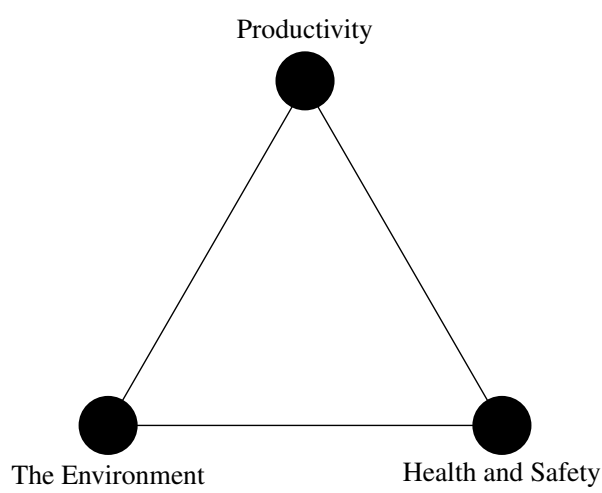

Fig. 1: The three areas of activity in a mining project.

lates to productivity. As part of a process of continual improvement of positions which have an impact on worker health and safety, as well as productivity, mining ventures take their inspiration from industrial trends to modernize their production. In effect, a major challenge of mining operations, logistics, takes up a significant part of the means and costs dedicated to the operation of a mine. Whether a question of the implementation of a process to improve the allocation of fixed resources, for the efficient use of physical assets or even for the rational use of human and financial resources in order to optimize production, the current trend is to put in place 'lean production' [27]. These logistics are totally compatible with information and communications technologies [24] one of which is augmented reality.

It is in this context that we involved ourselves in the mining field. We undertook participative observation with respect to two interacting types of position.

The first position involved is that of the operator of the power shovel, whose task it is to collect minerals with which to load the high-capacity trucks. The second position involved is the position of the truck driver. Individuals in these two positions work closely with each other during the entire cycle of production, from the posting of the truck to the loading zone, through to its arrival at the unloading zone. Within the framework of this pure production mode, the hypothesis is that augmented reality will find its place making better use of work stations, allowing an increase in profitability for operators, in a way that is congugee with the health and safety of the latter. The purpose of this study being to propose the changes necessary for the use of an augmented reality system as part of improvement in the productivity or the safety of workers.

\section{AUGMENTED REALITY}

A definition anchored in technology, but still commonly accepted in the field, [2] suggests that augmented reality encompasses systems capable 1) of combining the real and the virtual, 
2) of being interactive and 3 ) of offering $3 \mathrm{D}$ registration. It is commonly accepted today, that the third point does not necessarily need to be complied with, for an augmented reality system to exist. However, we prefer a more anthropocentric approach, which consists of defining augmented reality not by way of its technological characteristics, but by way of the effect it has on the user. In this sense, the purpose of augmented reality is to enable a person to carry out sensorimotor and cognitive activities in a mixed space, which combines real and artificial environments. Generally speaking, it may be a matter of developing the human ways of perceiving, thinking about and interacting with the physical world. augmented reality can offer either a modelling of the real world, based on a world that mimics or symbolizes certain aspects of the real world, or the creation of an imaginary world [14][16]. Primarily, augmented reality is made up of sensory devices capable of stimulating the user's senses (helmets, glasses, speakers, etc.) and motorized devices able to capture the movement of the user (inertial navigator platform, video camera, etc.).

\section{OPEN-PIT MINE}

Generally-speaking, the life cycle of a mine includes a series of steps, from the time it begins operations, until the time it shuts down. These are illustrated in Figure 2 The first step is an exploratory phase. The following step consists of developing the mine with a view to its operation, in the next phase. The final step enables the mine to be closed, by rehabilitating the site to a state of environmental compliance. In Figure 2, excerpted from [19], some blocks are shaded, in gray, to highlight the steps for which we are hypothesizing the potential for use of augmented reality, over the life cycle of a mining project.

\subsection{Exploration}

The exploration phase consists of determining the grade of raw materials in a potential working zone. The rock is first sounded using ultrasonic devices in order to discover its major constituents, and subsequently by core sampling, to refine the mapping of the raw material.

\subsection{Development}

This is the planning and mine construction phase. Among other things, planning factors in the necessary investments, the mine's chronological extraction process, as well as needs related to material, financial and human resources. In the construction phase, the buildings and infrastructure necessary for the processing of minerals, from the first set of crushers to the foundry, are erected.

\subsection{Operations}

The operations phase is the mine's main working phase. During this phase, needs in terms of resources will be most significant. The number of staff will be at its highest, and greater financial investments will be made.

\subsection{Closure}

The mine closure phase consists of cleaning up the operations zone in accordance with environmental regulations. Polluted zones are rehabilitated, and among other things, excavation work allows the different access points to the site to be made safe, or for the rehabilitation of certain zones, making them suitable for public access.

As part of this study, we were on-site during the operations phase, but it seems certain that augmented reality offers great potential for the exploration phase. This phase consists of determining if and in what proportions the ground contains natural resources. augmented reality also offers great potential for the

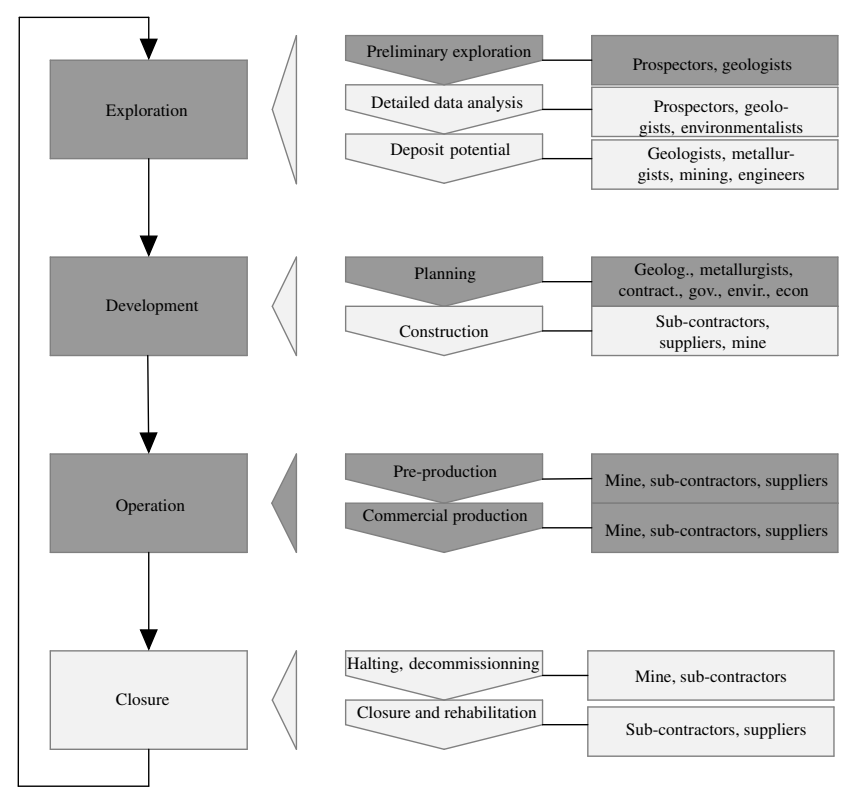

Fig. 2: Life cycle of a mining project, excerpted from [19], based on [30]. Shaded areas define the parts where augmented reality could be useful during the life cycle.

planning phase. The use of augmented reality as part of the exploration and planning phases could be the subject of a future study.

The mining sector is in the process of expanding rapidly. Canada, and particularly the province of Quebec, are an example of that expansion. In effect, Figure 3 illustrates the number of mining projects in the process of being started in Quebec (Source: Government of Quebec). The reason for this explosion in growth can be traced back to one major factor: the dynamics of raw material prices, which are greatly on the increase, gold being the most significant among these. Figure 4 clearly shows the change in gold, which has multiplied by 50 over the course of the last 40 years.

This change in price has led exploration ventures to re-open sites which had been abandoned because the grade of the raw material was no longer high enough to make the activity of extraction a profitable one. The "OSISKO Canadian Malartic" project [22] illustrates this type of situation. Initially, the "Canadian Malartic" deposit was discovered in 1926. Subterranean development started in 1928, and operations began in 1935, coming to an end in 1951. Barrick Gold [10] acquired the zone at the beginning of the 1990s. But all projects were suspended until 2003, the date of the sale of the deposit. Osisko finally re-purchased the zone at the end of 2004. The Canadian Malartic deposit now belongs to Osisko. It is the only subterrannean, high-tonnage gold-bearing deposit in the province of Quebec. Today, it is worked by the longhole method, to a depth of 350 metres, and limited to zones with a high mineral content. Operations are anticipated to last approximately 15 to 20 years. Gold-bearing reserves and the length of time they are worked make the Osisko project the largest mining project in Canada. The reader should know the fact that the scope of this project is clearly limited to open-pit mines, and specifically, to the Osisko mine [22]. If environmental, as well as productivity- and safety-related constraints are also present in subterrannean mines, the logisitics are different enough from those implemented in an open-pit mine, so that a dedicated study of these aspects is needed. 


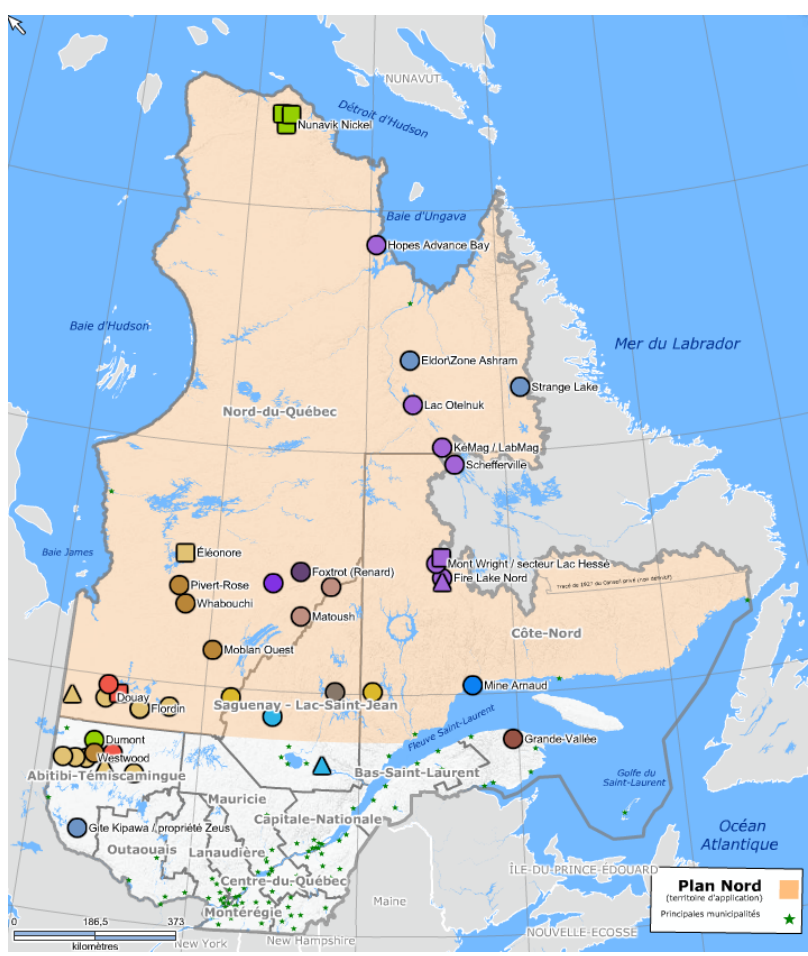

Fig. 3: The 44 mining projects in Quebec (June 2012, Source: Government of Quebec).

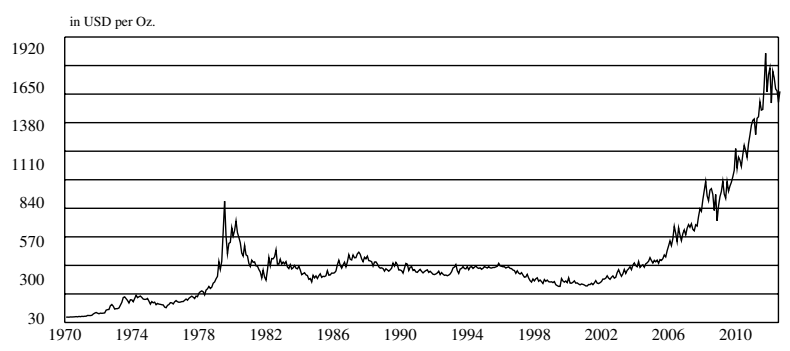

Fig. 4: Change in the value of an ounce of gold over the last 40 years.

\subsection{Constraints}

Osisko is faced with numerous operational constraints. Besides its listing on the stock exchange, the venture must take the presence of the town of Malartic, on the edge of the operations zone, into account, as well as the presence of former subterrannean mining sites. Also, the government imposes strict regulations on the venture with regard to vibration, noise and the generation of dust. In addition, the operation of the mine was approved by the government on the condition that a site previously polluted by operations would be cleaned up. One of the first uses of augmented reality in this context, would be with respect to the management of the site, from an environmental point of view [32]. All of these constraints have a direct impact on the work of mine operations. As a modern mining company, Osisko is obligated to obtain the best possible rate of gold production, at the same time as it guarantees the health and safety of its workers and of all people working in the vicinity. Because of this, the venture is innovating, in terms of tools and methods, either to improve productivity, or to improve worker health and safety. A number of specialized skill areas exist in an open-pit mine, which we propose to survey in the following sections. For each skill area, a description will be proposed to highlight how augmented reality could be used, and the developments required for this technology, to be able to promote its use in the mining sector.

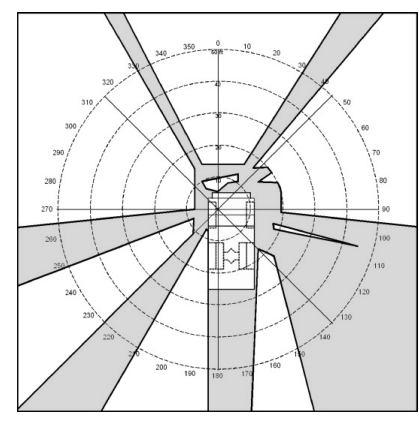

Fig. 5: Detail of the blind spots (see gray zones) which exist in a mining transport truck.

\section{THE PRIMARY SKILL AREAS IN THE MINING SECTOR}

The mining sector requires synergy among a number of different skill areas. In the list that follows, we will describe the primary skill areas required for work in an open-pit mine. The order of the primary skill areas is linked directly to the number of people belonging to each skill area, according to the CSMO [8].

\subsection{Heavy Machine Operators (Mobile or Fixed)}

5.1.1 Tasks. This job consists of driving and operating (both hands and both feet are used) machines that are extremely heavy (several hundred tonnes) and very large. The operators of these machines are the starting point for the handling of the minerals. Operators of mobile machines must manoeuver their machines from the loading zone to the unloading zone. They must follow the instructions of the onboard software to know where they are needed, or to know where to take their load, for example.

5.1.2 Use of augmented reality. Operators must deal with one major problem: Lack of visibility. Onboard these giant machines, which weigh several hundred tonnes, operators must deal with significant blind spots as illustrated by the shaded areas in Figure 5 In many situations, drivers must manoeuver "blind", guided only by their experience.

The use of augmented reality to solve this type of problem is attractive. In effect, the authors of [31 proposed the use of a projector-based display system in the driver's cabin to reduce blind spots. However, the constraints of this solution do not allow for its use in the mining context. Besides the difficulty in equipping the cabin, it is not possible for an operator to carry, on their head, for a whole 12-hour work day, all of the equipment necessary to implement this solution (camera, video projector, inertial sensor, etc.). The cables necessary for the operation of the equipment may get in the operator's way. What is more, it is necessary to carry out significant adjustments to the equipment for each driver, which is not compatible with the "driver hot-swaps", carried out so as not to slow down production.

5.1.3 Improvements. In this respect, efforts must still be made with regard to the development of sensory devices. Their weight and size, as well as the difficulties related to their adjustment are still signficant limitations to the use of this type of equipment by an operator of heavy machinery working in a severely-restricted industrial situation.

\subsection{Drillers and Dynamiters}

5.2.1 Tasks. This job consists of drilling the rock using portable machines or self-supporting drills. Drill holes in the 


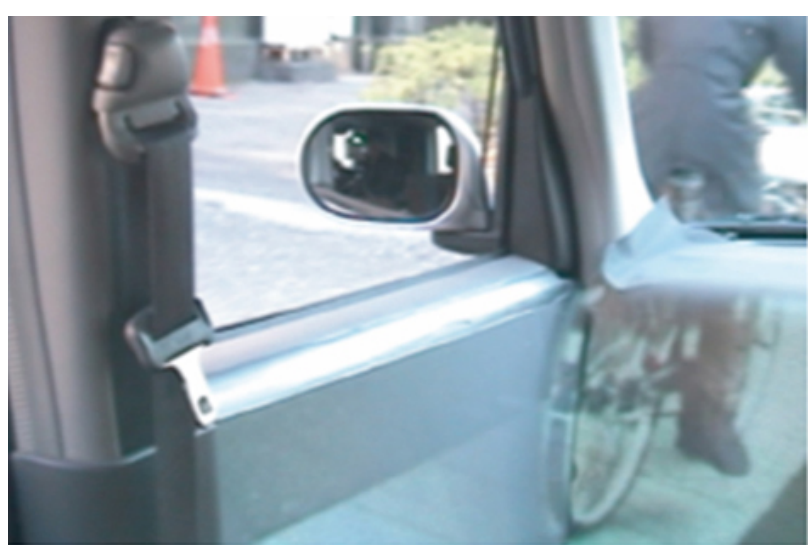

Fig. 6: System proposed by [31] to reduce blind spots.

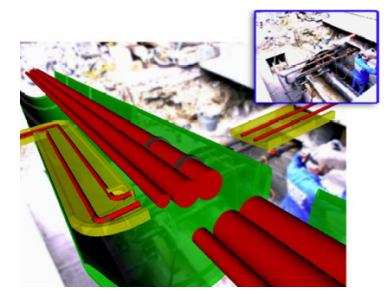

(a) Vidente project [26]

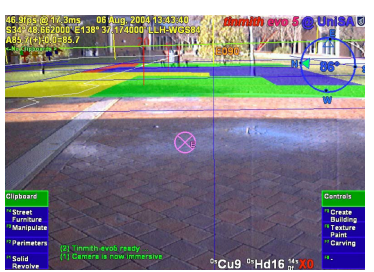

(b) ARVino project 17
Fig. 7: Two examples of the visualization of subterrannean information.

rock are positioned according to a drilling pattern defined by geologists in accordance with the state and type of rock, as well as the desired result. The drillers must therefore follow the drilling pattern as closely as possible. These patterns indicate the drilling diameters, diameters of the explosives used, the charge, hole depths, the gap between drill holes or the overall shape of the zone to be exploded. This work has a strong influence on the quality of the material after the explosion, but also on the vibration and the noise generated during the explosion.

5.2.2 Use of augmented reality. Similar to what is done in the field of public works, we think that augmented reality could be used to enable drillers to ensure that the positioning of the drill holes is correct. The goal of using augmented reality in this context would be to limit the different transits currently needed, between the site and the paper or electronic plans, for definition of the drill pattern (Figure 7). The use of a portable device can be envisioned in this context.

5.2.3 Improvements. The lack of free software, or of a framework enabling the implementation of such a system is certainly a limitation to the use of augmented reality, in this context. However, solutions proposed by [18, 29] for example which, although fairly rigid, are viable, insofar as it is possible to automate the creation of geolocalized points of interest in these platforms, from the points and the zones of interest defined in the different software used for the creation of drilling plans.

\subsection{Heavy or Fixed Machinery Mechanics}

5.3.1 Tasks. The mechanics are in charge of the preventive and corrective maintenance for the production machines. The unplanned shutdown of a heavy machine has extremely significant financial consequences in this type of mining project. Therefore, preventive maintenance plays a very important role, as does the responsiveness of the maintenance teams, and the upgrading of their knowledge regarding new models. As well, if the mining project takes place in a remote area, the onsite presence of an expert is often rare, and the arrival onsite of an expert can sometimes take several days.

5.3.2 Use of augmented reality. The first uses of augmented reality rightly took place in the field of manufacturing [6] or maintenance aid [9, 23]. Besides the fact that augmented reality minimizes reliance on paper media or on the direct consultation of a computer tool during the maintenance task, augmented reality makes it possible for an expert to remotely guide an onsite technician in conditions which are an improvement upon the use of a simple telephone [4, 5, 25].

5.3.3 Improvements. The mining context does not offer specificity with regard to maintenance, except for work on machines whose size is sometimes extraordinary. Correspondingly, the use of an augmented reality system for maintenance aid, in this sector, would be subject to the same constraints present in other sectors of activity where maintenance is necessary.

\subsection{Mining Technicians}

5.4.1 Tasks. The tasks of a mining technician are varied. As planners, mining technicians are called on to plot the mine's ramps and access points. In some cases, the mining technician will need to participate in the diversion of existing roads. The mining technician also participates in drawing up drilling plans for drillers and dynamiters. The use of computer tools is now generally-accepted practice, enabling technicians to use computer-aided design software in doing so.

5.4.2 Use of augmented reality. During exterior work, the use of augmented reality could help technicians deal with all of the constraints related to public works [11, 1], excavation work [17] or those related to artwork [13].

5.4.3 Improvements. In this context, there are no specific improvements to be made to the use of augmented reality, other than those which are well-known by the community.

\subsection{Geotechnology}

5.5.1 Tasks. Still in the context of an open-pit mine in a zone subject to prior, subterranean operations, geotechnological technicians must make the site safe, to map out and identify former subterranean mining sites. Three concentric lines are marked out, defining the zones in which safety procedures differ from one another. The defined area between the L1 and L2 boundaries requires individuals who want access to it, to be equipped with a safety harness and to be attached to a ground anchor system, where the zone closest to the centre requires the use of a "lifeline"-type system which enables the individual to be supported by a crane above the zone.

5.5.2 Use of augmented reality. During the mining operations phase, sometimes boundaries are moved, without the geotechnicians' approval. They must therefore ensure that the position of the lines is consistent with the plans, which requires sometimes very exacting, point-by-point verifications. The use of augmented reality enables the technician to easily verify that the boundary points on the site are still in place.

5.5.3 Improvements. The development of a software process enabling the use of georeferenced data leading towards an application of augmented reality remains a limitation due to a lack of internal competence, and time. A generic framework, enabling the automation and simplification of this aspect, which is necessary for the use of an augmented reality solution, should make its use in this particular case easier. 


\section{PERSPECTIVES}

In this article, we discussed the applicability of augmented reality in one of the phases (the operations phase) in the life cycle of a mining project. However, we hypothesize that augmented reality could be a significant asset in terms of the environment, safety and, to a lesser extent, productivity, in the other phases of the life cycle, presented in Section 4 We refer, for example, to the exploration phase and, more specifically, to the preliminary explorations (these being slowed down by the need for an exact knowledge of what is underground) as well as to the development phase.

\section{CONCLUSION}

In this article, we described the mining field and more specifically, an open-pit mine. After describing the circumstances of the current dynamic of the mining sector, and its consequences, we put forward an overview of the different skill areas, and of the activities in which augmented reality could make a significant assistive contribution. Then, supported by our onsite observations, we proposed courses of action to improve augmented reality technologies, so as to optimize their applicability in the mining sector. More specifically, we advocate the use of touchsensitive tablets when an activity needs to be mobile, and equipping the cabins of excavation machines and mineral transport trucks with projection-based systems.

\section{REFERENCES}

[1] H. Behzadan Amir and R. Kamat Vinett. Georeferenced Registration of Construction Graphics in Mobile Outdoor Augmented Reality. Journal of Computing in Civil Engineering, 21(4):247-258, July 2007.

[2] Ronald Azuma. A Survey of Augmented Reality. Presence: Teleoperators and Virtual Environments, pages 355-385, August 1997.

[3] Sébastien Bottecchia, Jean-Marc Cieutat, and Jean-Pierre Jessel. T.a.c : Système de réalité augmentée pour la téléassistance collaborative dans le domaine de la maintenance. AFRV08 Bordeaux, pages 133-138, Octobre 2008.

[4] Sébastien Bottecchia, Jean-Marc Cieutat, and Jean-Pierre Jessel. Experimentation of a new teleassistance system using augmented reality. In Virtual Reality International Conference (VRIC 2010), pages 163-170, Laval, France, 2010.

[5] Sébastien Bottecchia, Jean-Marc Cieutat, and Jean-Pierre Jessel. T.A.C: augmented reality system for collaborative tele-assistance in the field of maintenance through internet. In $A H$ '10: Proceedings of the 1st Augmented Human International Conference, pages 1-7, New York, NY, USA, 2010. ACM.

[6] T.P. Caudell and D.W. Mizell. Augmented reality: an application of heads-up display technology to manual manufacturing processes. In System Sciences, 1992. Proceedings of the Twenty-Fifth Hawaii International Conference on, volume ii, pages 659-669 vol.2, jan 1992.

[7] Jean-Marc Cieutat, Olivier Hugues, and Nehla Ghouaiel. Active learning based on the use of augmented reality outline of possible applications: Serious games, scientific experiments, confronting studies with creation, training for carrying out technical skills. International Journal of Computer Applications, 46(20):31-36, May 2012. Published by Foundation of Computer Science, New York, USA.

[8] CSMO. http://www.csmomines.qc.ca/accueil. html 2012.

[9] Steven Feiner, Blair Macintyre, and Dorée Seligmann. Knowledge-based augmented reality. Commun. ACM, 36(7):53-62, 1993.
[10] Barrick Gold. Barrick gold, 2012.

[11] Yan Guo, Qingyun, Yi Luo, Weiwei Zhang, and Lu Xu. Application of augmented reality GIS in architecture. The International Archives of Photogrammetry, Remote Sensing and Spatial Information Sciences, XXXVII(Part B5):331336, 2008.

[12] Steven J. Henderson and Steven Feiner. Evaluating the benefits of augmented reality for task localization in maintenance of an armored personnel carrier turret. Mixed and Augmented Reality, IEEE / ACM International Symposium on, pages 135-144, 2009.

[13] Tobias Höllerer, Steven Feiner, Tachio Terauchi, and Gus Rashid. Exploring mars: developing indoor and outdoor user interfaces to a mobile augmented reality system. Computer and Graphics, 23:779-785, 1999.

[14] Olivier Hugues. Réalité Augmentée pour l'Aide à la Navigation. SIGMA : Système d'Information Géographique Maritime Augmenté. $\mathrm{PhD}$ thesis, Université de Bordeaux 1, Pôle recherche ESTIA, Décembre 2011.

[15] Olivier Hugues, Jean-Marc Cieutat, and Pascal Guitton. An experimental augmented reality platform for assisted maritime navigation. In AH '10: Proceedings of the 1st Augmented Human International Conference, pages 1-6, New York, NY, USA, 2010. ACM.

[16] Olivier Hugues, Philippe Fuchs, and Olivier Nannipieri. New augmented reality taxonomy: Technologies and features of augmented environment. In Borko Furht, editor, Handbook of Augmented Reality, 10.1007/978-1-46140064-6_2, pages 47-63. Springer New York, 2011.

[17] Gary King, Wayne Piekarski, and Bruce. Thomas. Arvino - outdoor augmented reality visualisation of viticulture gis data. In ISMAR '05: Proceedings of the 4th IEEE/ACM International Symposium on Mixed and Augmented Reality, pages 52-55, Washington, DC, USA, 2005. IEEE Computer Society.

[18] Layar. http://www.layar.com/, 2010.

[19] Sylvie Nadeau, A. Badri, and André. Gbodossou. A mining project is a field of risks: a systematic and preliminary portrait of mining risks. International Journal of Safety and Security Engineering2012, 2012.

[20] 3DVia Nestle. Minimoys : http://minimoys.3ds.com/ press/3DVIA-Nestle.html 2010.

[21] ABC News. Mining boom here to stay. says $R B A$, www.abc.net.au/news/stories/2010/02/24/2828545.htm, 2010.

[22] Osisko. Osisko canadian malartic, 2012.

[23] Juri Platonov, Hauke Heibel, Peter Meier, and Bert Grollmann. A mobile markerless ar system for maintenance and repair. In ISMAR '06: Proceedings of the 5th IEEE and ACM International Symposium on Mixed and Augmented Reality, pages 105-108, Washington, DC, USA, 2006. IEEE Computer Society.

[24] Jan Riezebos, Warse Klingenberg, and Christian Hicks. Lean production and information technology: Connection or contradiction? Comput. Ind., 60(4):237-247, May 2009.

[25] Nobuchika Sakata, Takeshi Kurata, and Hideaki Kuzuoka. Visual assist with a laser pointer and wearable display for remote collaboration. In Proceedings of 2 nd international conference on Collaboration Technologies (CollabTech 2006), pages 66-71, 2006.

[26] Gerhard Schall, Erick Mendez, Ernst Kruijff, Eduardo Veas, Sebastian Junghanns, Bernhard Reitinger, and Dieter Schmalstieg. Handheld augmented reality for underground infrastructure visualization. Personal and Ubiquitous Computing, Special Issue on Mobile Spatial Interaction, 13(4):281-291, Mai 2008. 
[27] Rachna Shah and Peter T. Ward. Defining and developing measures of lean production. Journal of Operations Management, 25(4):785-805, June 2007.

[28] Richard Wetzel, Rod McCall, Anne-Kathrin Braun, and Wolfgang Broll. Guidelines for designing augmented reality games. In Proceedings of the 2008 Conference on Future Play: Research, Play, Share, Future Play '08, pages 173-180, New York, NY, USA, 2008. ACM.

[29] Wikitude. http://www.wikitude.org/, 2010.

[30] Yukon Mine Training Association (YMTA). The mine cycle, ww. yukonminetraining.com/career training_seekers/mining_in_the_yukon/the_ mine_cycle/, 2010.
[31] Takumi Yoshida, Kensei Jo, Kouta Minamizawa, Hideaki Nii, Naoki Kawakami, and Susumu Tachi. Transparent cockpit: Visual assistance system for vehicle using retroreflective projection technology. In $V R^{\prime} 08$, pages 185-188, 2008.

[32] I. Zendjebil, F. Ababsa, Jean-Yves Didier, J. Vairion, L. Frauciel, M. Hachet, Pascal Guitton, and R. Delmont. Outdoor Augmented Reality: State of the Art and Issues. 10th ACM/IEEE Virtual Reality International Conference (VRIC2008), Laval : France, pages 177-187, 2008. 